\title{
Cross-Generational Negotiations: Asian Australian Picture Books
}

\author{
Clare Bradford
}

Children's texts habitually hinge upon narratives of growth and development, modelling to their readers how children and young people become autonomous and other-regarding individuals. In Australian literature for children these narratives of development are often inflected by the cultural and ideological shifts which have informed discussions around Australianness, citizenship, and identity since 1972, when the Whitlam government enunciated its vision of a multicultural nation. An important strand in Australian publishing for children has been the production of texts featuring protagonists who identify as members of ethnic minorities. Treating as normal the assumptions and values of minority cultures, such texts at their best enable children from these cultures to experience narrative subjectivity, while positioning children from mainstream culture to engage with plurality and difference.

Within the growing body of work on cultural citizenship, several theorists including Stevenson (2003) and Pakulski (1997) have emphasised that cultural production enables members of different ethnic groups to engage in dialogue. Stevenson points out that 'many in the social sciences have neglected the idea of the imagination' and its capacity to create 'webs of meaning that are carried by societies institutions and individuals' (2003, p. 132). He calls for an education in citizenship that enables 'the creative cultural production of the subject and an ethics of dialogue' (p. 346). Children's texts are pre-eminently suited to providing such an education in citizenship, especially since children introduced to texts in educational settings are frequently invited to engage in discussions of books and their significances.

A cursory glance at the many Australian websites offering lists of 'multicultural books' reveals that such books are generally defined as multicultural solely on the basis of their themes and content (see Bradford 2006). Yet, as Stevenson notes, 'it is not enough to point to processes of cultural democratisation, as important as these might be, but one should also be concerned with questions related to meaningfulness, quality and aesthetics' $(2001$, p.6). The celebratory approaches to 'multicultural books' apparent in website lists of such books confine themselves precisely to 'processes of cultural democratisation', as though narratives which represent relationships between protagonists of different cultures and ethnicities are unproblematically 'multicultural'.

To approach questions related to 'meaningfulness, quality and aesthetics' in children's books, I focus in this discussion on a group of books for younger readers, all of which involve narratives structured by interactions between Asian Australian children and their grandparents: Xingyi Mo and Morag Loh's Grandpa and Ah Gong (1995); Di Wu and Allan Baillie's Old Magic (1996); Di Wu and Jing Jing Guo's Grandpa's Mask (2001); and Sally Rippon's junior novel What a Mess, Fang Fang! (1998). Grandparents figure prominently in realist children's texts thematising diasporic experience. They serve as vehicles for the narration of family histories, often providing a point of comparison with the parent generation. Most crucially for my purposes, represented interactions between grandparents and children or young people enable texts to propose ideas and values around change, continuity and cultural meanings.

All four of the texts I discuss were published between 1995 and 2001; that is, from just before the 1996 election which brought the Howard government to power, and up to 2001, the year of the Tampa crisis and 9/11; and hence, over a period of heated debate around multiculturalism and migration. Picture books of this period tended to locate depictions of multiculturalism within the domain of everyday life, showing how growing individuals are gradually introduced to a wider world of social and cultural interaction, with potential for conflict as well as personal growth. In contrast, recent and contemporary Australian picture books thematising multiculturalism have focused more on processes and rhetorics which marginalise those regarded as different, often with reference to refugee populations. The currency of this approach is evident in the following 2007 texts, all of which thematise refugee experiences: Helen Manos and Max Maxfield's Lucky Baby Yak (2007); Czenya Cavouras's Rainbow Bird (2007); Gabiann Marin and Jacqui Grantford's A True Person (2007) and Liz Lofthouse and Robert Ingpen's Ziba Came on a Boat (2007).

In picture books of the kind I discuss in this essay - those which focus on the everyday experiences of children growing up in a multicultural society - cultural 
diversity is very often symbolised by objects or artefacts whose production and meanings involve crosscultural negotiations. In OldMagic, Omar creates a kite for his kakek, or grandfather; in Grandpa and Ah Gong, Mandy's two grandparents (Malaysian and Australian) together construct a kite for her; and in Grandpa's Mask the child protagonist creates a mask on her grandfather's face. In What a Mess, Fang Fang!, the object in question is a little jade cat owned by Fang Fang's grandmother. On one hand these objects stand for the cultural backgrounds of grandparents; on the other, they represent the interaction of practices and cultures experienced by child protagonists. Stevenson (2001), Turner(2008 forthcoming), and Crossley (2001) emphasise that cultural citizenship depends upon intersubjectivity, since, as Crossley says, 'to be a citizen is to recognize the other as an autonomous, self-conscious being' (2001,p.34). Turner draws on Hegel's social philosophy, which he argues, 'provides a powerful analysis of the process of recognition of others which creates a framework for recognising the cultural rights of others in a context of cultural pluralism and social diversity' (2008, forthcoming). Grandparents are not other to their grandchildren in these texts, since they are bound to them by ties of kinship and affection; nevertheless, interactions between them are informed by differences of experience and perspective and negotiated through external objects or markings.

The children in these texts live in Australian settings, a habitus established as Western and modern. In Old Magic, Omar wears the paraphernalia of the skateboarder and carries a basketball' ${ }^{1}$; in Grandpa and Ah Gong, Mandy plays ball with her Australian Grandpa (her mother's father) and visits his neighbour Mrs Pianto in a setting whose lawn, paling fence and shrubbery evoke 1950s suburbia. Grandpa's Mask begins with a flashback to the time when the first-person narrator lives with her family, including her Grandpa, 'in a village in China', but then shifts to an Australian setting. Here she watches Peking Opera on videotapes that her Grandpa imports, but 'the excitement gradually wore off as I played the same tapes again and again'. In What a Mess, Fang Fang!, Fang Fang runs away from home (though only as far as her grandmother's house) because she feels that her mother compares her unfavourably with her twin cousins, Ling
May and Ling Sun, who are 'better at everything' (1998, p.3) than Fang Fang: playing the piano; schoolwork; and especially using chopsticks. Old Magic, Grandpa and Ah Gong and Grandpa's Mask feature grandfathers whose clothing, appearance and behaviour render them to various degrees exotic in everyday Australian settings, signifiers of difference not assimilated into an Anglo national identity.

In Old Magic and Grandpa and Ah Gong, narratives turn on tensions between the cultural norms of grandparents and those of the host country. Old Magic addresses these tensions directly in Omar's rejection of the spinning top offered to him by Kakek, his grandfather:

\section{The kakek wound a long braided cord around a painted disc of wood. \\ 'I am remembering, boy. I am remembering the magic.' \\ 'We don't do that any more, 'said Omar. 'Nobody does that any more.'}

When the kakek accuses Omar of remembering nothing of their life in Indonesia, the boy recalls growing up in the village, where there was 'no TV, no computer games, no pizza' but instead shadow puppets, night markets, and days spent fishing with Kakek. Omar spends all the money he has saved to buy wire, hoops, ribbons, glue, paint and plastic, some of which 'would never be seen in the jungle village', and constructs a kite which he presents to the kakek.

\section{'Have I remembered, Kakek?' asked Omar. \\ 'Have I remembered the fighting paper birds, the swooping demons, the lions in the air?'}

The kakek laughed and took one of the lines from Omar's hands. 'You have not forgotten anything, boy. Let us swallow the sun.'

Throughout the book up to this point, the illustrations have shown Omar and the kakek separated by physical spaces which represent the distance between the two. Dancing above the 'flat and lonely beach' of the Australian setting, Omar's kite brings the boy and his grandfather together, their bodies overlapping and echoing each other in a display of mutuality: 
Omar and his grandfather - his kakek - played the great kite across the empty sky, dancing together.

\section{Even if Omar was listening to his headphones.}

The final sentence of the narrative points to the idea that Omar's experience of flying the kite is shaped by his cultural affiliations, which embrace Malay and Australian practices and signs: not only does he listen to his headphones, but the kite's construction includes plastic and 'even tabletennis balls' as well as wire, ribbons, paper. To his kakek, however, the kite is a reassuring sign of Omar's maintenance of memory and tradition. Omar's creation of the kite is prompted by an act of recognition which incorporates both his memories of the 'old magic' of his childhood, and his sense of his grandfather's experience of loss and sadness. By reaching out to his kakek Omar shows himself to be capable of imagining his perspective, and as he moves away from focusing merely on his own interests he also re-values the cultural richness of village life. The idea of a polyglot identity is thus at the core of the narrative and is advocated through its closure.

Di Wu's illustrations evoke an Australian setting where both the built environment and the beach are conspicuously empty of human life, compared with the lively village of Omar's childhood. However, the vast beach of the final doublespread is also a space in which 'old magic' can fill the 'empty sky', a utopian possibility underscored by the facial expression of the kakek. If Omar's clothes locate him within Western youth culture, the illustrations foreground the kakek's Muslimidentity through his clothing and appearance: his green jacket; his turban; the patterns of stars and crescent on his sleeve; the sarong he wears over his wide trousers. The signifiers of Malay Muslim culture woven into text and illustrations thus point toward a model of citizenship inclusive of religious as well as ethnic diversity, an idea which has become increasingly contentious since the publication of Old Magic.

Whereas the narrative of Old Magic is built around the play of symbols, Grandpa and Ah Gong focuses on crosscultural relations within the family of the protagonist, Mandy, who has an Australian and a Malaysian grandfather. When Ah Gong travels from Malaysia to visit Mandy and her parents, the two grandfathers 'seemed very happy to meet each other' and engaged in joint activities. However, their differences of habit and cultural expectations soon emerge: for instance, Ah Gong cannot see the point of running unless he's in a hurry; while Grandpa finds tai chi 'too slow'; Ah Gong goes to sleep at the netball while Grandpa nods off at an exhibition of calligraphy. The first outward sign of tension occurs when they watch a kite with Mandy:

'That's a very plain kite, 'Ah Gong said. 'Kites in Malaysia are much prettier. They look like birds and butterflies.'

'I suppose you think we should do things the Malaysian way!' Grandpa spoke so sharply I looked at him instead of at the kite.

Ah Gong shrugged and said, 'Maybe.'

Mandy worries because her grandfathers are unaccountably too busy to meet her after school, but the narrative resolves when the two present her with the kite which they have been working on together, a kite like a butterfly. At the end of the story, when Mandy's mother asks Grandpa and Ah Gong whether the kite is for Mandy or themselves, Grandpa's reply 'For all of us' underlines the narrative's agenda in a somewhat heavy-handed way.

Mandy is the first-person narrator, and the limitations of her perspective are suggested through illustrations where she is depicted as unaware of the tensions between the two grandfathers, whereas readers can observe their facial expressions and demeanour. Thus, the scene in which $\mathrm{Ah}$ Gong shows the family how to do tai chi shows Grandpa, unobserved by Mandy, looking on with an expression suggestive of amusement or puzzlement. The narrative is staged as a series of events and settings coded either as 'Australian' or 'Malaysian' (for instance, jogging or tai chi; netball or calligraphy), producing the impression of cultures defined in binary terms. Mandy's identity-formation, then, seems to be constituted as a kind of patchwork of discrete cultural elements. Because the production of the kite takes place, as it were, offstage, we know nothing about the negotiations which have been involved in its making, so that the kite functions more as a symbol of what the two grandfathers have in common - their devotion to their granddaughter - than of cultural dialogue. Moreover, 
because Mandy is the object of their affection and the recipient of the kite, she is passive and without agency, deriving pleasure from their accord but not engaging with the intersubjective relations involved in the process of creation. The habitus suggested by the illustrations, with their details of Anglo suburban life, constructs Ah Gong as an exotic presence; moreover, as a visitor whose temporariness anticipates the family's return to normality (that is, to whiteness) when he departs for Malaysia. His status as an exotic visitor obscures any questions about the diasporic experience of his son (Mandy's father), who is subsumed into whiteness.

A somewhat similar representational mode, involving a grandfather whose presence is a reminder of an exotic elsewhere, is evident in Grandpa's Mask. As the note at the end of the book discloses, the story on which this picture book is based won the 1997 Nestle Write Around Australia Creative Writing competition when Jing Jing Guo was in Year Six. The story, in brief, tells how one day when the protagonist's grandfather is looking after her, he dozes off while watching television. The protagonist uses her mother's makeup to create a mask on Grandpa's face, similar to the Peking Opera masks which she has often watched with him. When the alarm on his watch sounds, he wakes and goes out to carry out his daily task, collecting groceries from the local shopping centre, oblivious to the brightly-coloured paint on his face. After the girl's grandfather returns to China he sends her a carved opera mask based on the one she created.

As in his illustrations for Old Magic, Di Wu shows a sharp contrast between the family's country of origin, and the Australian setting. In the scene in which the protagonist and her grandfather watch Peking Opera in his home in China, they are framed by the open window, almost as though they themselves perform as audience. This illustration refers to traditions of performance and design: the artifice of the actors and their painted faces; the natural materials (timber, paper, tiles) of the house. The two figures, encircled in the bamboo backrests of their chairs, are located in relation to these traditions and drawn into the imaginative world of the opera as the characters impinge on the everyday setting. The doublespread showing the two watching Peking Opera in the family's home in Australia, in contrast, presents a subdued and muted built environment in which aluminium and steel dominate instead of natural materials. The opera, too, which has lost its capacity to fill the domestic space, is reduced merely to images on the television screen.

When the girl paints her grandfather's face, she introduces some of the glamour and colour of the Chinese setting into the mundane Australian world, but the most startling images of the book show Grandpa, oblivious to the effect he creates, walking to the shopping centre. This episode is depicted in the book's cover blurb as no more than an amusing interlude, and the book's final illustration shows the girl smilingly holding up the mask which her grandfather has sent her. Yet the scene of Grandpa's walk to the shopping centre is a challenging image to read in relation to ideas of intersubjectivity. The fact that Grandpa's is an unwitting performance, observed by characters and readers, works against the possibility of recognition. Moreover, his spectacular difference and the expressions of shock or discomfort on the faces of the shoppers construct him not merely as other but as unreadable, since the mask separates him from those he encounters.

Of the three picture books I've so far discussed, only Old Magic addresses the complex negotiations which result when one person recognises another (to return to Hegel's theory of recognition) as possessing cultural rights. The kakek's desire for cultural maintenance is answered by Omar's openness to the possibilities of a polyglot identity. In contrast, Grandpa and Ah Gong concludes with the universalising proposition that the love of grandparents for their grandchildren transcends difference; and in Grandpa's Mask, cultural difference is as superficial as the mask painted on Grandpa's face. In What a Mess, Fang Fang!, the emphasis is rather on relationships in Fang Fang's extended family, and on the strains which exist when Fang Fang feels that she is compared unfavourably with her cousins. Although the setting is recognisably Western, Fang Fang's identity as an Asian Australian child is treated as a given in this text (in her two other 'Fang Fang' books, Rippin deals overtly with questions of affiliation and belonging).

The green jade cat which is the central symbol in the narrative belongs to Fang Fang's grandmother. At the 
beginning of the narrative Fang Fang is 'cross' because her mother compares her unfavourably with her twin cousins:

\section{If Fang Fang ate wontons and her cousins ate wontons, it was always Fang Fang who dropped soy sauce on her top.}

'What a mess, Fang Fang!' her mother would say. 'Why can't you be clean like your cousins?'

(pp.1-2)

It is because of her sense that she does not live up to her mother's expectations that Fang Fang runs away to her grandmother's house. When she spills soy sauce on her top while eating the wontons her grandmother has made, she discloses her anxiety by bursting into tears, whereupon her grandmother reassures her and fetches another top. The contrast between mother and grandmother makes a subtle point about the propensity of parents to hold out high expectations of children, and to focus on external behaviours, an emphasis underlined at the end of the book, when the tables are turned and Fang Fang's twin cousins are the messy ones:

Their mother was very cross with them. 'What a mess!' she said. 'Why can't you be clean like Fang Fang?'

(p.48)

Because unreasonable parental expectations are not confined to Chinese parents, it is open to readers of all ethnicities to align their experience with Fang Fang's. Nevertheless, all the characters featuring in this episode are members of a diasporic Chinese family, so that it is feasible to see interactions between the children and their mothers in this text as inflected by particular (diasporic) anxieties.

When Fang Fang goes to bed wearing her grandmother's top, she finds in its pocket 'a small green stone, cut into the shape of a cat' (p.22). She decides to keep the stone cat' so that 'she would have something special to show her cousins' (p.24). At school she keeps it in her pocket, but her feeling of guilt prompts her to surreptitiously replace it in the pocket of her grandmother's top. When the family (Fang Fang, her parents, her cousins and their parents) gather at her grandmother's house for wontons, her grandmother puts 'a very big wonton in Fang Fang's bowl' (p.38), to the amusement of her cousins, who take this as an indication of Fang Fang's inferior skills with chopsticks. Inside the wonton is the green stone cat. Her grandmother tells her: 'To find a green jade cat in your wonton is lucky. It's like magic! It looks as if you will have to keep it!' (p.43).

Grandmother's recognition that Fang Fang needs affirmation is, at the level of plot, the catalyst for her action. But the gift of the jade cat is also coded as Chinese, and Nai Nai's action can thus be read as a reminder to Fang Fang that she is a diasporic subject affiliated to the country of her birth: 'Fang Fang picked up the small cat made of jade. It felt cool. She was very happy. She felt very special' (p.44). To add to Fang Fang's satisfaction, when her cousins frantically open up all the wontons in search of similar treasures, they get soy sauce on their tops. Like the kite in Old Magic, the jade cat functions as a symbol both of familial bonds and of polyglot identities, since even as it speaks of Chinese traditions, Fang Fang treats it as a talisman which accompanies her as she moves between home and school.

It is in Rippin's depictions of the school setting that Fang Fang is seen in the context of an 'Australian' and multicultural community, where the presence of her cousins is an unwelcome reminder of her mother's criticism. Rippin's sunny depiction represents the school as a version of an Australia where children of various ethnicities play and learn together: Fang Fang's friend Rick shows her a lizard, and during 'Show and Tell' time the other children listen interestedly when Fang Fang puts up her hand to show the jade cat. However, the presence of her cousins inhibits her so that when the teacher says 'Yes, Fang Fang?', Fang Fang replies 'Um ... nothing', whereupon her cousins giggle, drawing unwelcome attention to her. It seems, then, that membership of the overlapping communities of school and family occasions tension for Fang Fang because the relationships and allegiances of these two communities are not necessarily aligned.

When Omar in Old Magic takes it upon himself to construct a kite which will show his grandfather that he 
remembers 'the old country', the text models a way of negotiating across traditions and practices; when Fang Fang's grandmother gives her the talisman of a jade cat, the narrative points to the emotional connection between them, which transcends their differences of age and experience. Characters in these texts are busily concerned with making: kites; a mask; wontons; and this emphasis suggests that cultural citizens too construct themselves, as Stevenson says, by learning to move 'within multiple and diverse communities' (2001, p.2). The limitations of the picture book form - and in the case of What a Mess, Fang Fang!, the junior novel - mean that these texts struggle with representing the social and cultural complexities of diasporic experience. Nevertheless, in the way of children's literature more generally, they gesture toward a surplus of meaning, an excess of significations, because they draw upon the knowledge and experience of the adults who produce them, and they seek to provide pleasure while socialising young citizens.

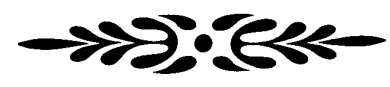

\section{NOTES}

1. Almost universally across Australian websites and in secondary material relating to 'multicultural books' and referring to Old Magic, the 'old place' from which Omar and his kakek have come is assumed to be China. See, for instance: 'Picture Book Families', from the website 'The Australian Family', http://archive.amol. org.au/theaustralianfamily/pbf/essay01.htm; 'South Australian Premier's Reading Challenge’, http://www. premersreadingchalleng.sa.edu.au/; and

Stella Lees, 'God's One Country: The Depiction of Asians by Australian Children's Authors', The La Trobe Journal, 60, Spring, 1997, p. 67.

Yet the visual references in the illustrations, as well as the text's use of the Malay word 'kakek', clearly point to a Malay Indonesian setting. This confusion is symptomatic of how 'Asian' and 'Chinese' identities are homogenised and subsumed in much mainstream writing on multiculturalism.

\section{REFERENCES}

Baillie, A. and D. Wu (1996) Old Magic. Milsons Point. Random House.

Bradford, C. (2006) 'Multiculturalism and Children's Books', in J. Zipes (ed) The Oxford Encyclopedia of Children's Literature, Vol. 3. New York, Oxford University Press, pp. 113-118.

Crossley, N. (2001) 'Citizenship, Intersubjectivity and the Lifeworld', in N. Stevenson (ed) Culture \& Citizenship. London, Sage, pp. 33-46.

Guo, J. J. and D. Wu (2001) Grandpa's Mask. Melbourne, Benchmark.

Loh, M. and X. Mo (1995) Grandpa and Ah Gong. South Melbourne, Hyland House.

Pakulski, J. (1997) 'Cultural Citizenship', Citizenship Studies 1.1, 73-86.

Rippin, S. (1998) What a Mess, Fang Fang! London, Southwood.

Stevenson, N. (2003) 'Cultural Citizenship in the "Cultural” Society: A Cosmopolitan Approach', Citizenship Studies 7.3, 331-348.

(2001) 'Culture and Citizenship: An Introduction', in N. Stevenson (ed) Culture and Citizenship, London, Sage, pp. 1-10.

Turner, B. (2008, forthcoming) 'Rights, Recognition and Relativism', in W. Ommundsen, M. Leach and A. Vandenberg (eds), Cultural Citizenship and the Challenges of Globalisation.

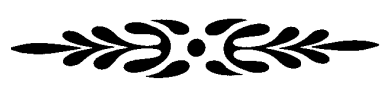

\section{BIOGRAPHICAL NOTE}

Clare Bradford is Professor of Literary Studies at Deakin University in Melbourne, Australia, where she teaches literary studies and children's literature and supervises students undertaking MA and $\mathrm{PhD}$ programmes. She has published widely on children's literature, with an emphasis 
on postcolonial literary theory and its implications for reading colonial and postcolonial texts. Her book Reading Race: Aboriginality in Australian Children's Literature (2001), won both the Children's Literature Association Book Award and the International Research Society for Children's Literature Award. Her most recent books are Unsettling Narratives: Postcolonial Readings of Children's
Literature (2007), and New World Orders: Utopianism and Contemporary Children's Texts (with Mallan, Stephens and McCallum) (2008). She is the President of the International Research Society for Children's Literature (IRSCL).

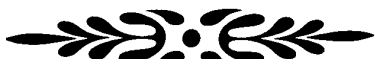

